more than maintenance and total average production of 1 gal. daily per cow. The National Milk Costs Investigation (Milk Marketing Board, 1953) shows that on the average almost $3 \frac{1}{2} \mathrm{lb}$. of concentrates are fed for every gal. of milk produced throughout the year. Over the winter period the rate was $4 \frac{1}{4} 1 \mathrm{~b}$. for every gal. and $2 \mathrm{lb}$./gal. throughout summer. The national situation, therefore, is that all winter milk is produced on concentrates and in summer grazing provides for an average daily production of less than $1 \frac{1}{2}$ gal. per cow.

All classes of grazing animal can be pastured more intensively than is the common practice in British farming. This implies growing more grass throughout the season over a longer season, and sustaining high nutritive quality of the herbage for animals with substantial requirements for production, i.e. milking cows and fattening stock. The technical methods of achieving these ends are now well tried, though it would be foolish to claim that no practical problems remain to be solved in producing and using the grass so as to satisfy optimum physiological needs of the animal and in integrating these factors in order to obtain greater output in the most profitable way. Greater progress has been made in postwar years in evolving the ways and means of exploiting more efficiently our greatest national farming asset; the more urgent remaining problem is to secure their incorporation in general farming practice.

\title{
REFERENCE
}

Milk Marketing Board (I953). National-Investigation into the Economics of Milk Production. Cost of Milk Production in England and Wales, October, 1950, to September, 195 I. Thames Ditton, Surrey: Milk Marketing Board.

\section{The Economical Rearing of Dairy Heifers}

\section{By J. A. Crichton and J. N. Aitken, Rowett Research Institute, Bucksburn, Aberdeenshire}

The economical rearing of dairy heifers is more than a question of the amount of money spent on food, housing and labour to bring an animal to first calving. The value of a heifer at calving is probably about one-eighth only of the value of the milk she will produce during an average milking life, say of three and a half lactations, and although the cost of rearing is not an unimportant item in the economy of the farm it will always be a very variable one according to the price and kind of foodstuffs available at any given time. We know much about how to keep costs low without visibly affecting the health of the young stock, e.g. by the use of milk substitutes and cheap fodders. But if the environment, of which feeding is a part, during rearing should appreciably reduce the value of future milk productionirrespective of genetic capacity-it may be of the greatest importance in determining what is true economy in the feeding of dairy heifers.

Unfortunately there is little information on the effect of environment and especially feeding during the growth period on the production and health of dairy cows. 
Bonnier, Hansson \& Skjervold (1948) of Sweden, using one-egg twins, reported the effects on the subsequent lactations of feeding heifers on high and low planes of nutrition during growth. In one experiment all animals after calving were fed according to yield and body-weight but with no provision for the difference in rates of growth that might have been expected between the two groups. The high-plane cows yielded as a rule more fat-corrected milk than their low-plane twin sisters. The low-plane animals, however, when well fed after calving grew faster so that the total production of energy, i.e. milk yield plus gain in weight, was equal for the two groups. In the second lactation the difference between the two groups was smaller, and for the third lactation it was not significant. It is suggested that these results were due to a decreasing demand on food for growth as the animals reached maturity. Flux (I950), using six pairs of twins to determine the effect of underfeeding during a period of ro weeks before calving, found that the poorly fed animals produced less milk than their well-fed sisters. The composition of the milk in fat, protein and lactose was not affected. In another experiment by Bonnier et al. (1948), however, the differences between the planes of nutrition were continued after calving, and under these circumstances the differences in weight between the two groups continued to increase after 30 months of age. The yields of the low-plane animals were not significantly lower than those on the high plane. This suggests that the inherited capacity of the high-plane experimental animals to produce milk was very low and the small differences between the planes of nutrition had no marked effect. At the Ruakura Station, New Zealand (Filmer, I952) heifers reared on low and high planes of nutrition were subdivided at calving into two groups and fed on either a high or a low plane so that there were four groups during the milk-production period. The poorly reared cattle produced almost as well as their well-reared mates when subsequently fed on a high even level of nutrition.

Hansson, Brännäng \& Claesson (1953) in an analysis of several feeding experiments with one-egg twins concluded that rearing intensity has a considerable influence on the rate at which an animal develops and this in turn influences the length of life in favour of the more slowly growing animal. This statement is based on the survival to 75 months of nine high-plane twins and to 95 months of nine low-plane twins, but we are not given as much information as we would like on the causes of disposal. Hansen \& Steensberg (1950) obtained somewhat similar results using groups of fifty to sixty unrelated animals, but again there were complicating factors.

\section{Experiment at the Rowett Research Institute}

To obtain more information on the nutritional economy of dairy cattle as affected by the method of rearing, a long-term experiment with one-egg twins is now in progress at the Rowett Research Institute.

Experimental procedure. The experiment was begun in 1949 using eighteen pairs of one-egg and six pairs of two-egg twins. Four different rearing systems are being compared. These may be defined as follows: (I) a continuous high level of nutrition 
from birth to first calving $(\mathrm{HH})$; (2) a high level of nutrition for the first Io months followed by a low level until 2 months before calving (HL); (3) a continuous low level of nutrition until 2 months before calving (LL); and (4) a low level of nutrition for the first to months followed by a high level thereafter ( $\mathrm{LH})$. All groups are 'steamed up' on a rising plane of nutrition from 2 months before calving.

During the first ro months and subsequent winter periods before calving, feeding is strictly controlled. In order to simulate normal farming practice as closely as possible all animals over Io months of age go to grazing in summer but we confine the low-plane groups to hill pasture while the high-plane groups are on good arable leys. The rations during the controlled feeding periods are based on standards published by Ragsdale (1934) of the daily intake of total digestible nutrients required by Ayrshire and Friesian cattle to obtain normal growth. During the highplane phases of feeding the heifers are offered $110 \%$ of this standard while the lowplane animals are allowed only $70 \%$ for the first 6 months and $60 \%$ thereafter.

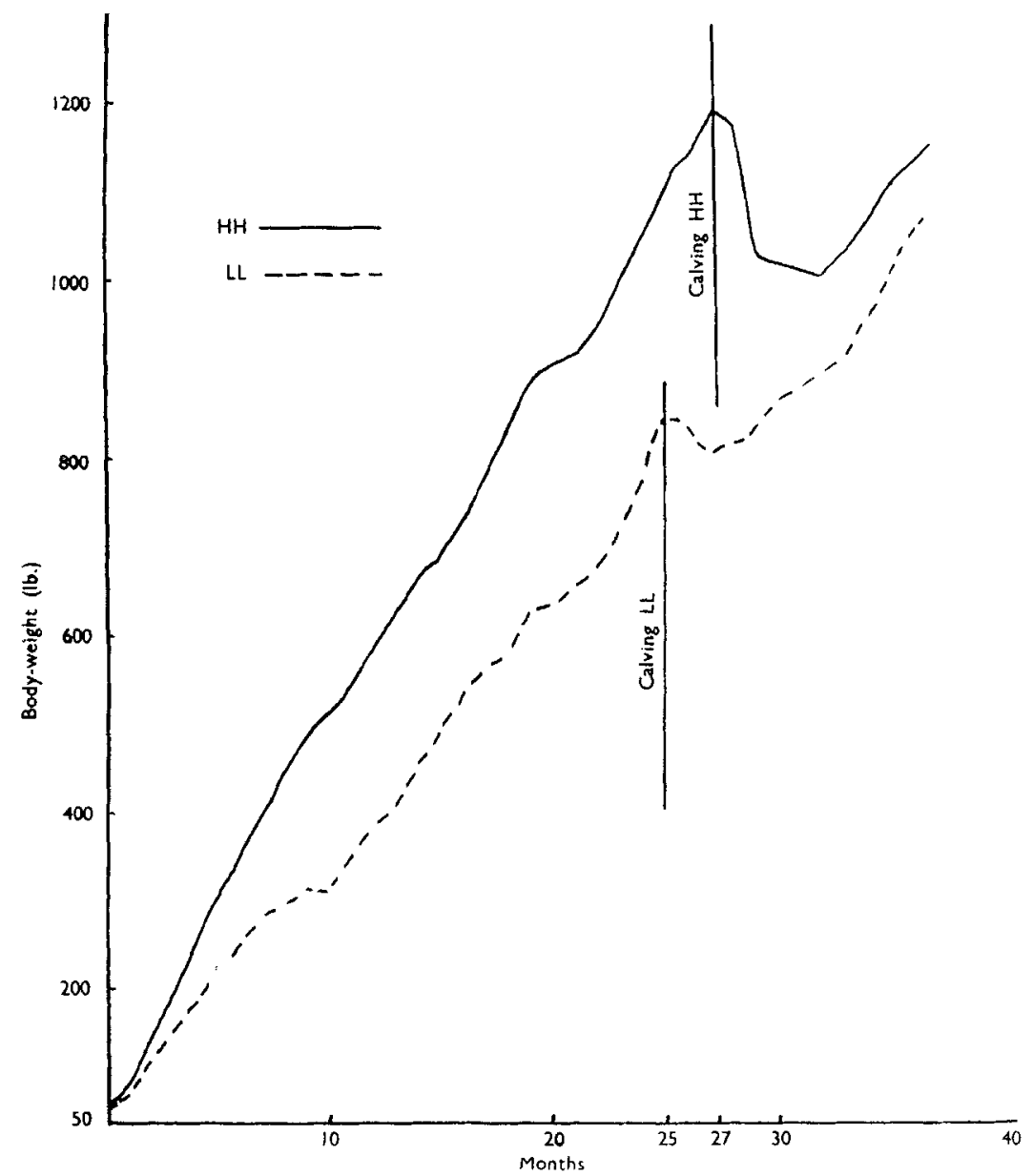

Fig. I. Within-pair difference in body-weight of heifers reared on a continuously high (HH) or continuously low (LL) plane of nutrition (averages of two pairs). 
The aim is that all heifers should calve at 26 months of age. The rationing of all animals during lactation is based on the Ministry of Agriculture feeding standards (Mackintosh, I938) but a maintenance ration slightly in excess of that recommended for a $1000 \mathrm{lb}$. cow is allowed to all animals.

Records. Feed consumption is recorded throughout the controlled-feeding periods. Body-weights and measurements are taken at regular intervals. Milk is weighed and sampled daily. Bulked portions are tested for butterfat and solids-notfat once weekly. Onset of first oestrus and breeding efficiency are recorded.

Results. Data for the first lactation are still incomplete but figures are available for body-weights and measurements. To illustrate the trends common to all groups Figs. I, 2 and 3 have been prepared. The average within-set difference in body-weight for the HH or LL groups is shown graphically in Fig. I. A maximum difference of nearly $300 \mathrm{lb}$. is reached at 20 months of age. This is reduced to only $75 \mathrm{lb}$. at 3 years of age though at this stage the weights are complicated by the second pregnancy. It will be seen that the high-plane animals lose considerably more weight at calving than their low-plane sisters.

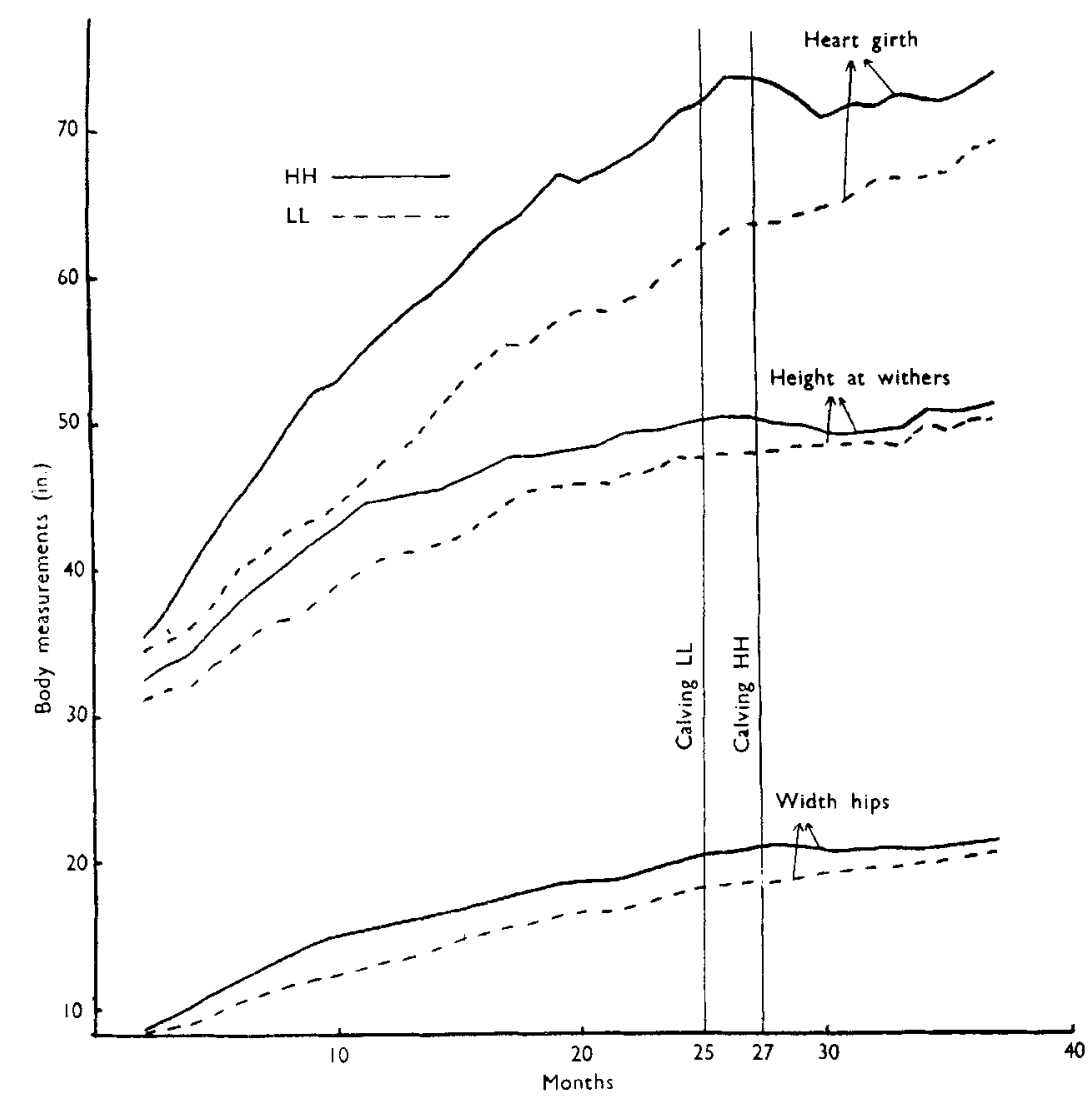

Fig. 2. Within-pair differences in body measurements of heifers reared on a continuously high (HH) or continuously low (LI) plane of nutrition (averages of two pairs). 
Body measurements are shown in Fig. 2. The heart-girth curves correspond almost exactly to those of body-weight. Height at withers and width between hips are, however, a more accurate measure of skeletal development. It will be seen that a low plane of nutrition has retarded the rate of growth but has not caused permanent stunting, since the differences in these measurements have almost disappeared by 3 years of age. The increase in height at withers of the high-plane over the low-plane animals is not due entirely to greater bone development but must in part be due to increased deposition over the shoulder area of muscle or fat, or both. This is borne out by the temporary reduction in this measurement in the high-plane animals after calving. Fig. 3 shows the rapid recovery in skeletal size when animals change from a low to a high plane of nutrition. The evidence as far as it goes suggests that, as found by other workers, there may eventually be only a small difference in mature body-weight and such skeletal measurements as have been made between the high- and low-plane animals.

Data on the breeding efficiency of the animals in each group are shown in Table I. Age of sexual maturity was measured by noting the age at which each animal showed first oestrus. It will be seen that the low plane of nutrition delayed the onset of oestrus in the LL group on the average by $3 \frac{1}{2}$ months as compared with the

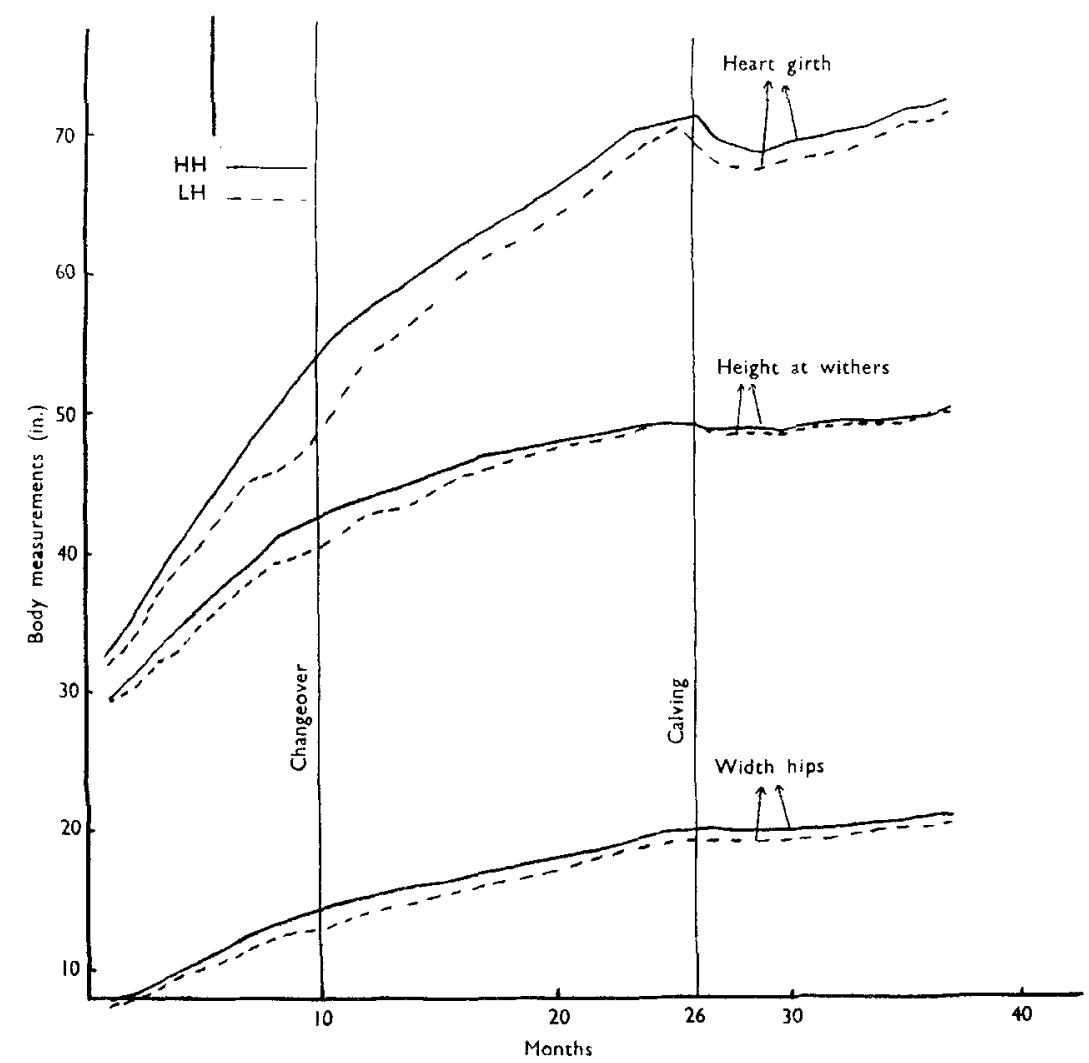

Fig. 3. Within-pair differences in body measurements of heifers reared on a continuously high (HH) or low-high (LH) plane of nutrition (averages of four pairs). 
Table 1. Breeding efficiency of heifers on varying levels of nutrition in the Rowett experiment

\begin{tabular}{|c|c|c|c|c|}
\hline \multirow[b]{2}{*}{ Gestation I } & \\
\hline & $\mathrm{HH}^{*}$ & $\mathrm{HI}$, & $\mathrm{L} \mathrm{H}^{*}$ & LL* \\
\hline Total no. of heifers & 14 & $\mathrm{~T} 2$ & 12 & 14 \\
\hline No. of fertile heifers & 13 & I 2 & I I & 14 \\
\hline No. in calf to first service & I I & IO & 10 & I I \\
\hline No. in calf to second service & 2 & 2 & - & 2 \\
\hline No. in calf to subsequent services & 一 & - & $\mathbf{I}$ & $\mathbf{I}$ \\
\hline \multicolumn{5}{|l|}{ Gestation 2} \\
\hline Total no. of cows & 12 & II & IO & 13 \\
\hline No. of fertile cows & 12 & 9 & yo & 13 \\
\hline No. in calf to first service & 8 & 6 & 6 & I 1 \\
\hline No. in calf to second service & 4 & 3 & 2 & 2 \\
\hline No. in calf to subsequent services & $\cdots$ & - & 2 & - \\
\hline Average age at first heat (months) & I 2 & 13 & 14 & I 5.5 \\
\hline Interval between first and second calvings (days) & 387 & $39 I$ & 395 & 410 \\
\hline
\end{tabular}

$\mathrm{HH}$ group. The range of age at first oestrus in the LL group was from I 2 to I 9 months. This is of some importance in practice. There is a growing tendency to calve down cows in the autumn to obtain more winter milk production, which means serving at about Christmas when autumn-born heifers are approximately i 5 months of age. They may not be on heat by that age if they have been on a low level of winter feeding during the months of October to December.

For the first and second pregnancies the overall conception rate to first or second service of all groups was high. Data on the birth weights of the first calves from the four groups have been statistically analysed. Birth weight was affected by length of gestation, but there was no significant difference between treatments although the weights of the calves from the LL group, after an adjustment had been made for length of gestation, were slightly lower than those of the calves from the other three groups. It must be remembered, however, that all the heifers were 'steamed up' for 2 months before calving when foetal gain in weight is most rapid.

\section{Conclusions}

It seems fairly firmly established that, although the level of feeding influences the rate of growth of dairy cows, it has little influence on ultimate size at maturity. Recovery in growth is very rapid when an animal moves from a low to a high plane of nutrition.

In several experiments reported in the literature, milk yield has been influenced in the first and, to a lesser extent, in the second lactation, but there is no conclusive information on the effect on total yield. We hope to report on this at a later date.

In the Rowett Institute experiment onset of first oestrus was delayed by about $3 \frac{1}{2}$ months in the low-plane as compared with the high-plane animals but thereafter fertility seemed to be unaffected.

It is tentatively suggested that economy in food, especially concentrates, during the more costly period of winter feeding can be practised without seriously affecting 
growth provided there is good summer grazing. If, however, it is necessary to serve heifers in midwinter to calve at 2 years of age in the following autumn, extra feeding in the form of concentrates may be necessary to ensure a high rate of fertility.

\section{REFERENCES}

Bonnier, G., Hansson, A. \& Skjervold, H. (1948). Acta agric. suec. 3, I. Filmer, J. F. (1952), Rep. Dep. Agric. N.Z. p. 8

Flux, D. S. (1950). F. agric. Sci. 40, 177.

Hansen, K. \& Steensberg, V. (1950). Beretn. Forsøgslab. Kbh. no. 246.

Hansson, A., Brännäng, E. \& Claesson, O. (r953). Acta agric. Scand. 3, $6 \mathrm{r}$.

Mackintosh, J. (1938). Bull. Minist. Agric., Lond., no. 42 (revised).

Ragsdale, A. C. (1934). Bull. Mo. agric. Exp. Sta. no. 338.

\section{Economies in Feeding for Milk Production}

By S. BARTLETT, National Institute for Research in Dairying, University of Reading

A widely used method of rationing milking cows in Britain during recent decades was to give the cow about $20 \mathrm{lb}$. of hay daily for maintenance and $3 \frac{1}{2} \mathrm{lb}$. of balanced concentrates for each gal. milk produced. In prewar days, this simple system was sound economically and nutritionally but it has now been rendered obsolete by the change in availability and in the relative values of home-grown food compared with purchased concentrates.

\section{Factors affecting the efficiency of the rumen}

In the same way that our conception of the cow's dietary needs was simplified by the hypothetical division of a ration into maintenance and production portions, so we may simplify our understanding of her digestive processes by picturing it in two sections, (a) the rumen and (b) the remainder of the digestive system. The latter section is similar to that of single-stomached animals and is chiefly of value to the cow for dealing with diets composed of concentrated foods. The former section (the rumen), however, is primarily concerned with the digestion of fibrous or bulky foods, now usually home-grown, and it is this portion that deserves special attention under present-day economic conditions. Three general lines of approach are suggested to improve the efficiency of the rumen fraction of the cow's digestive organs:

(I) To breed cows that are more efficient in digesting roughage foods, (2) to train cattle during their growth period to become more efficient in dealing with roughage, and $(3)$ to provide rations that ensure maximum efficiency of digestion and assimilation.

\section{Breeding}

Cows can be bred for almost any clearly defined quality, e.g. milk records provide a measure of milk-yielding powers and consequently it is reasonably easy 